\title{
Study of the effects of the hand grip and finger strengths on the friction and petrissage - the massage manipulations - of the students who take massage courses: Kütahya City example
}

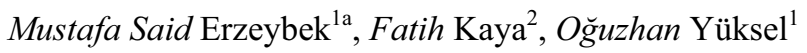 \\ ${ }^{1}$ University of Dumlupınar, Academy of Physical Education and Sports, Kütahya, Turkey \\ ${ }^{2}$ University of Erzincan, Faculty of Education, Department of Physical Education and Sports, \\ Erzincan, Turkey
}

\begin{abstract}
In this research, the effect of the hand grip and finger strengths on the power development between the friction and petrissage techniques the massage manipulations - have been studied. To the study that has been structured as a single group pretest/post test, 36 healthy males who are the students of the University of Dumlupinar, Academy of Physical Education and Sports and who take massage courses (age $=19.72 \pm 1.56$ years (average \pm Sd)) have been included. The practical massage course has continued for 12 weeks, two days a week for a total of one hour and the hand grip strength of both hands (right hand grip strength = RHG, left hand grip strength $=\mathrm{LHG}$ ) and the grip strength of both fingers (right finger strength $=\mathrm{RF}$, left finger strength $=\mathrm{LF}$ ) have been recorded at the beginning. For the measurements carried out before and later of the study with regard to the hand grip strength, a Takkei branded hand dynamometer and with regard to the finger grip strength a (baseline) branded pinch meter have been used. All measurements have been repeated twice and for the analysis, the average values obtained from two deads have been used. For statistical analysis, with regard to the changes in the pre test-post test finger strength and hand grip strength, paired-samples $t$ test has been used. The significance limit has been defined as $p<0.05$. For all values, the average, standard error and standard deviation have been used. It has been observed that the both hands' finger strengths and both hands' grip strengths have developed from the pre test phase to the post test phase $(\mathrm{p}<0.01)$ and these developments are similar for both hands' grip strengths and both hands' grip strengths ( $>00.05)$. It is possible to report that massaging regularly with both hands is efficient for the development of the finger and hand grip strengths; especially, with regard to the friction (circular movements that are generally carried out with fingers) and petrissage (kneading that is generally carried out with the palm) techniques.
\end{abstract}

${ }^{a}$ Corresponding author: msaid.erzeybek@dpu.edu.tr 


\section{Introduction}

The hand is one of the most important components affecting the functionality of the upper extremity. Among the hand functions, gripping is an important function for the continuity of the daily living activities [9]. For this reason, the gripping strength is accepted as an objective measure in terms of the evaluation of the upper extremity performance [4].

This method used by the doctors and physiotherapists in the clinics to follow up the clinical conditions of the patients with upper extremity injuries [5]. Also provides data for determining the treatment targets by the physiotherapists and occupational therapists, evaluating the efficiency of the treatment as well as specifying the level of competence for the job [13].

The conducted studies have shown that the hand gripping strength is correlated with the upper extremity muscle strength $[8,10])$ as well as the general muscular strength [12]. It has been reported that the fore arm volume, length, peripheral measurement, hand size as well as the age, body mass index and length are the estimation parameters for the hand grip strength [3].

The massage aims to relieve the pain, to reduce the swelling in a certain area, to relax the muscles, to accelerate the healing of the stretches and wrenches due to the physical injuries and carried out using the manual manipulations. The masseur/masseuse should regularly practice in order to be able to use his/her right and left hands with the same skill. When achieved, this would increase the efficiency. The masseur/masseuse would be less tired personally. During the massage, if the body weight is used for the pressure to be applied to the partner instead of the hand power, the masseur/masseuse would get less tired.

Massaging can be a very tiring profession. The masseur/masseuse who should give $8-$ 10 total massages per day has to care his/her personal health. Therefore, s/he should adopt the ergonomic working system. In order to prevent fatigue and back pain, the position during the massaging is important. In a correct position, the body weight is equally distributed on both feet. During the massage, the weight is transferred from one foot to the other and the load should be transferred to the wrist from the shoulder.

Massaging in a correct position would enable the protection of the backbone - waist health of the masseur/masseuse as well as increase the efficiency of the massage. The masseur/masseuse should be able to control his/her respiration through abdominal respiration while working.

Carpal Tunnel Syndrome (a median neuropathy trap with the symptoms such as paresthaesia, pain, numbness and others) is an occupational illness observed particularly among the data entry staff who has to work overtime, the translators who work long hours with the computer, the massage therapists who deals with long hours therapies, the musicians, especially those playing the instruments with fingers such as piano and guitar. The major issue is the contractio of the nervus medianus connected to the hand by the peripheral tunic in the carpal tunnel of the wrist.

Another important occupational illness is the Compartment Syndrome. This is caused by the over accumulation of pressure within a limited area of the body; this is mostly observed in arms and legs. The dangerously high pressure in the compartment syndrome prevents blood circulation to the tissues affected by the illness. This may cause an emergency and the patient may have to be operated for eliminating the risk of permanent results.

Also, Kienböck's Disease is the result of the decrease or cease of the blood circulation to the lunatum bone. Repetitive trauma (hit, strike, sprain, pressure, forcing, etc.) may influence the blood circulation. Also the Ganglions are mostly seen in gymnasts who have to apply force continuously on the wrist. If the cystic mass in the ganglion grows as to apply pressure to the nerve tissue in the joint, it may cause pain. 
In this research, the effect of the hand grip and finger strengths on the power development between the friction and petrissage techniques - the massage manipulations have been studied.

\section{Method}

The study has been conducted with 36 healthy male students from University of Dumlupınar, Academy of Physical Education and Sports who take massage courses (age = $19.72 \pm 1.56$ years, length $=176.94 \pm 5.01$, body weight $=75.92 \pm 4.09$ ). The hand and finger grip strengths of both hands of the participants have been recorded at the beginning and end of the study. The massage courses have been provided during 12 weeks, twice a week, one hour each.

For measuring the hand grip strength a Takkei branded hand dynamometer and for measuring the finger grip strength a (baseline) branded pinch meter have been used [5].All measurements have been repeated twice and the average has been calculated.

For statistical analysis, with regard to the changes in the pretest-post test finger strength and hand grip strength, paired-samples $t$ test has been used. The significance limit has been defined as $p<0.05$. For all values, the average standard error and standard deviation have been used. The SPSS software package has been used for the analysis.

\section{Results}

The Right Finger and Left Finger Strengths have been significantly changed from pretest to the post test phase $(\mathrm{t}(35)=-7.119, \mathrm{p}<0.01 ; \mathrm{t}(35)=-7.953, \mathrm{p}<0.01$, respectively) (Table 1 , Figure 1) and these developments were similar for both finger strengths $(\mathrm{t}(35)=-1.222$, $\mathrm{p}>0.05)$.

Table 1. The changes in the right and left finger strengths from pretest to the post test phase during the process. Mean $+/-$ Ss

\begin{tabular}{llcccc}
\hline & & Avr \pm Sd & t & sd & p \\
\hline $\begin{array}{l}\text { Right finger } \\
\text { strength }(\mathrm{kg})\end{array}$ & $\begin{array}{l}\text { pretest } \\
\text { post test }\end{array}$ & $\begin{array}{l}12.18 \pm .22 \\
13.02 \pm .19\end{array}$ & -7.119 & 35 & 0.000 \\
\hline $\begin{array}{l}\text { Left finger } \\
\text { strength }(\mathrm{kg})\end{array}$ & $\begin{array}{l}\text { pretest } \\
\text { post test }\end{array}$ & $\begin{array}{l}11.56 \pm .25 \\
12.59 \pm .16\end{array}$ & -7.953 & 35 & \multirow{2}{*}{0.000} \\
\hline
\end{tabular}

The right hand and left hand grip strengths have been significantly changed from pretest to the post test $(\mathrm{t}(35)=-9.739, \mathrm{p}<0.01 ; \mathrm{t}(35)=-7.908, \mathrm{p}<0.01$, respectively) (Table 2, Figure 2) and these developments were similar for both hand grip strengths $((\mathrm{t}(35)=-1.223$, $\mathrm{p}>0.05$ ), (Table 2).

Table 2.The changes in the right and left hand grip strengths from pretest to the post test phase during the process. Mean $+/-\mathrm{Ss}$

\begin{tabular}{|c|c|c|c|c|c|}
\hline & & $\operatorname{Avr} \pm$ Sd & $\mathbf{t}$ & sd & p \\
\hline \multirow{2}{*}{$\begin{array}{l}\text { Right hand } \\
\text { grip strength } \\
\text { (kg) }\end{array}$} & pretest & $55.60 \pm .84$ & \multirow[b]{2}{*}{-9.739} & \multirow[b]{2}{*}{35} & \multirow[b]{2}{*}{.000} \\
\hline & post test & $58.88 \pm .69$ & & & \\
\hline \multirow{2}{*}{$\begin{array}{l}\text { Left hand } \\
\text { grip strength } \\
(\mathrm{kg})\end{array}$} & pretest & $50.97 \pm .75$ & \multirow{2}{*}{-7.908} & \multirow[b]{2}{*}{35} & \multirow{2}{*}{.000} \\
\hline & post test & $55.03 \pm .67$ & & & \\
\hline
\end{tabular}




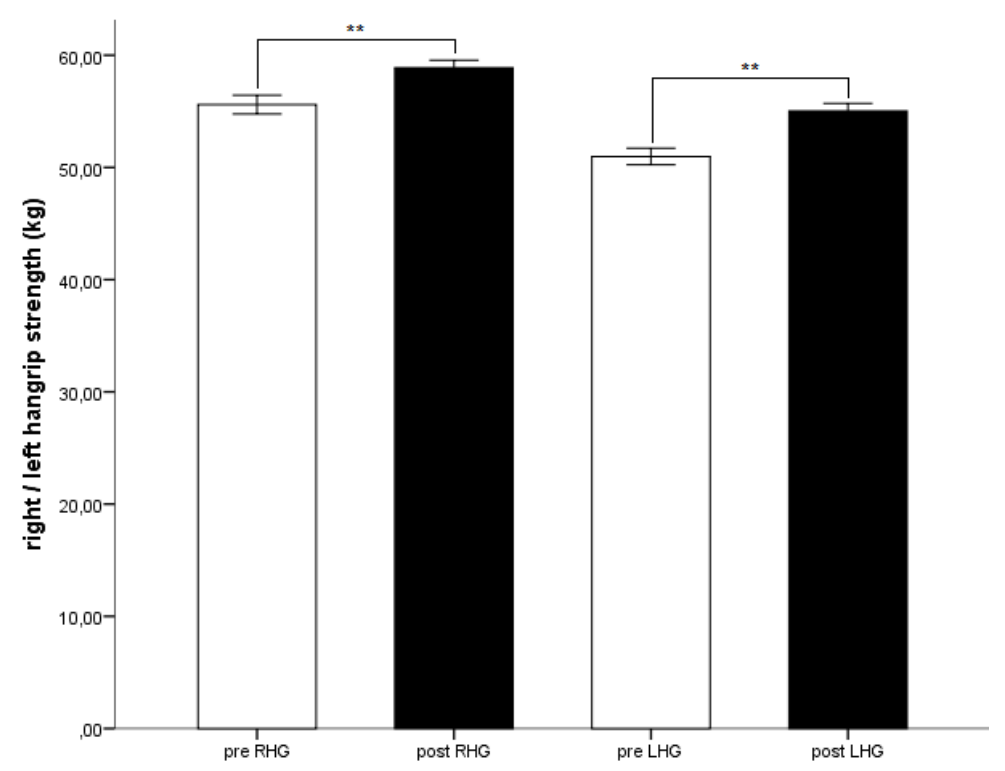

Figure 1. The average values of the right and left finger strengths obtained in the post test are higher than those obtained in the pretest, $* * \mathrm{p}<.01$. ( $+/-1 \mathrm{SE})$.

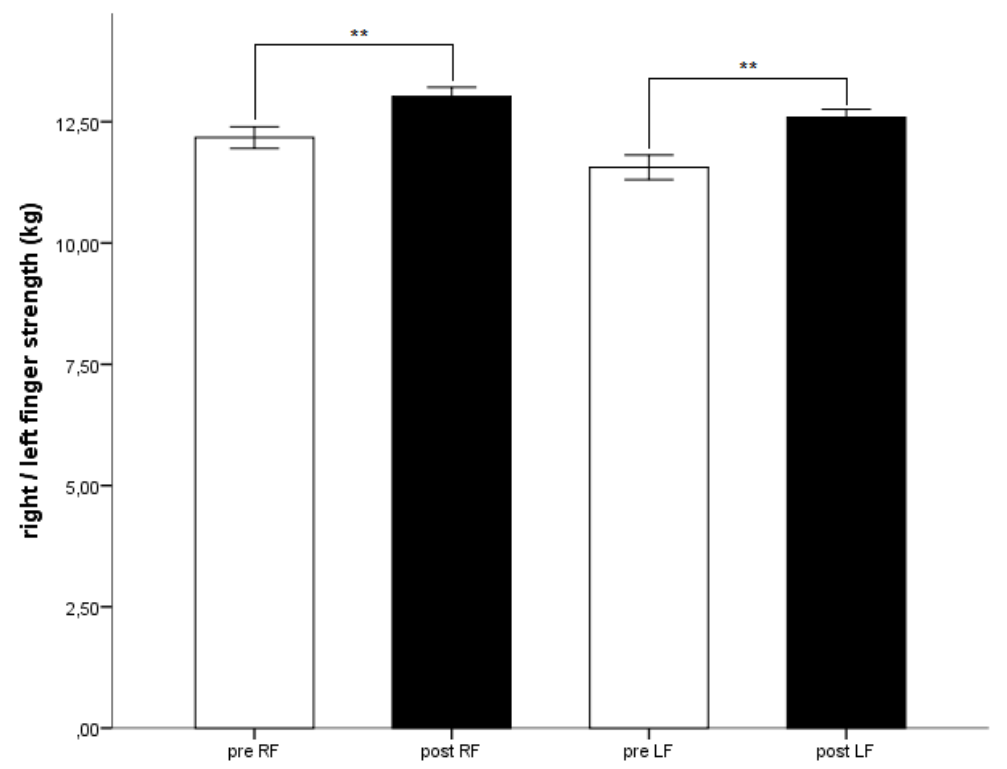

Figure 2. The average values of the right and left hand grip strengths obtained in the post test are higher than those obtained in the pretest, ${ }^{*} \mathrm{p}<.01 .(+/-1 \mathrm{SE})$. 


\section{Discussion and Conclusions}

Hand grip strength is very important to carry out most of the daily life activities [9]. Generally, the thumb helps to realize the functional capacity and fine skills of the hand. Peterson et al. has reported that the dominant hand's grip strength is $10 \%$ higher than to the nondominant one's grip strength [11].

Armstrong et al. has reported a difference of $0.1-0.3 \%$ between the dominant ve nondominant hands [1].The $10 \%$ rule reported by Peterson et al. is only valid for those who use their right hand as dominant [11]. Whereas both hands' grip strengths are equal for those who use their left hand as dominant. 30 of the participants included in our study were using their right hands and 6 of them were using their left hands as dominant and they were in the similar age interval.

The effects of the anthropometric factors (forearm length, forearm peripheral measure), sex, hand dominance, length, body mass index and age etc. on the hand and finger grip strength have been reported in the literature [2,5,7].

Similar to the hand grip strength measurement, finger grip strength measurement is also frequently used to evaluate the hand functions. The finger grip strength is also associated with the anthropometric factors such as forearm length and finger length [6].

If there is any strength development difference or such trend, it is possible to say that the frequently encountered diseases such as carpal tunnel syndrome, compartment syndrome that are related with the wrist or forearm damages can be reduced with the strength development. For developing the grip strength, the wrist extensors and long flexor muscles of the fingers should work together. For creating isometric power while gripping, the participation of the wrist extensors is required. Similar to the hand grip strength, the finger grip strength also shows the capacity of the hand functions [6].

Consequently, it is possible to report that with regard to the both hand manipulations, massaging regularly with both hands is efficient for the development of the finger and hand grip strengths; especially, with regard to the friction (circular movements that are generally carried out with fingers) and petrissage (kneading that is generally carried out with the palm) techniques.

\section{Suggestions}

Masseur/masseuze shall perform certain warm up exercises to prepare his/her hand muscles and $\mathrm{him} / \mathrm{herself}$ before massaging, if $\mathrm{s} / \mathrm{he}$ just starts massaging.

For example;

- Punching and opening the fingers by stretching, 25 times.

- Stretching the fore arm muscles while the palms are adhered. Keeping 20 seconds and then release, 10 times.

- While the hands are united via fingertips, pulling the hands in the reverse direction. This position is kept for 20 seconds and then released, 10 times.

- The diverse exercises regarding particularly the forearm and hands would facilitate the physical adaptation process of those who will work as professional masseur/masseuse.

- Besides, an experienced masseur/masseuse would protect him/herself against possible injuries by preparing his/her muscles with this kind of exercises before the first massage of the day. 


\section{References}

1. CA Armstrong, JA Oldham. A comparison of dominant and non-dominant hand strengths. J Hand Surg [Br] 1999; 24:421-425.

2. RE Anakwe, JS Huntley, JE McEachan. Grip strength and forearm circumference in a healthy population. J Hand Surg Eur Vol 2007;32:203-209.

3. LE Charles, CM Burchfiel, D Fekedulegn et al. Occupational and other risk factors for hand-grip strength: the Honolulu-Asia Aging Study. Occup Environ Med 2006; 63:820-827.

4. YF Gabriel Ng, CCF Andy. Does elbow position affect strength and reproducibility of power grip measurements? Physiotherapy 2001;87: 68-72.

5. JC Gilbert, RG Knowlton. Simple method to determine sincerity of effort during a maximal isometric test of grip strength. Am J Phys Med 1983; 62:135-144.

6. CM Günther, A Bürger, M Rickert, CU Schulz. Key pinch in healthy adults: Normative values. J Hand Surg Eur Vol 2008;33: 144-148.

7. NA İncel, E Ceceli, PB Durukan, O Öken, HR Erdem. El kavrama gücüne cinsiyet ve el dominansının etkisinin değerlendirilmesi. Romatizma 2002;17: 12-16.

8. D Mandalidis, M O'Brien. Relationship between handgrip isometric strength and isokinetic moment data of the shoulder stabilisers. J Bodywork Mov Ther Xxx,Xxx (article in pres) 6

9. CW Nicolay, AL Walker. Grip strength and endurance: Influences of anthropometric variation, hand dominance, and gender. Int J Ind Ergon 2005;35: 605-618. 2

10. M Sinaki. Relationship of muscle strength of back and upper extremity with level of physical activity in healthy women. Am J Phys Med Rehabil 1989;68:134-138.

11. P Peterson, M Petrick, H Connor, D Conklin. Grip strength and hand dominance: challenging the $10 \%$ rule. Am J Occup Ther

12. G Sahin, B Ulubas, M Calikoglu, C Erdoğan. Handgrip strength, pulmonary function tests, and pulmonary muscle strength in fibromyalgia syndrome: is there any relationship? South Med J 2004;97:25-29

13. SW Wu, SF Wu, HW Liang, ZT Wu, Huang S. Measuring factors affecting grip strength in a Taiwan Chinese population and a comparison with consolidated norms. Appl Ergon $\mathrm{xxx}, \mathrm{xxx}$ (article in pres) 5 